\section{Research Square \\ Preprints are preliminary reports that have not undergone peer review. \\ They should not be considered conclusive, used to inform clinical practice, or referenced by the media as validated information.}

\title{
Effect of Anticipated Lifestyle and Income on Medical Students' Decision to Pursue a Primary Care Career in Saudi Arabia
}

\author{
Ahmed Alhussain ( $\square$ ahmedaa@email.sc.edu ) \\ University of South Carolina \\ Ronnie D. Homer \\ University of Nebraska Medical Center \\ Abdullah T. Khoja \\ Imam Muhammad ibn Saud Islamic University \\ Janice C. Probst \\ University of South Carolina \\ Robert R. Moran \\ University of South Carolina
}

\section{Research Article}

Keywords: Medical education in Saudi Arabia, Career choice, Lifestyle, Income, Primary care

Posted Date: February 25th, 2021

DOI: https://doi.org/10.21203/rs.3.rs-246830/v1

License: (c) (7) This work is licensed under a Creative Commons Attribution 4.0 International License. Read Full License 


\section{Abstract}

Background: This study examines factors that influence Saudi Arabian medical school students in their selection of primary care as their career specialty. We focused on the two main factors identified to influence medical students generally in consideration of career specialty: lifestyle and income. We surveyed all fourth- and fifth-year students at 10 medical schools in the Riyad region using a questionnaire regarding factors influencing their intended specialty choice; 1005 (64\%) completed the questionnaire.

Results: The clear majority ( $77 \%$ of students) considered lifestyle characteristics to be a significant influence in their career decision to enter a specialty versus primary care $(P<0.05)$. There was also significant relationship $(p<0.005)$ between students' specialty choices and importance attached to anticipated income.

Conclusion: Lifestyle and income consideration are important influences on specialty selection among 4th and 5th year Saudi Arabian medical students. These results are in consistent with findings of previous studies conducted in many nations around the world.

\section{Introduction}

As in nations elsewhere, Saudi Arabia is experiencing a shortage of primary care providers and is seeking guidance as to ways to increase the number of medical students electing to practice primary care versus a specialty. Social and economic factors are increasingly being studied to identify those factors most influential on medical students' career choice, notably in the US. However, few studies of specialty choice among Saudi medical students explore the relationship between social and economic factors and selection of primary care. Those studies that do examine social or economic factors treat these factors descriptively. Thus, it is uncertain whether and how social and economic factors actually influence primary care career choice among medical students in Saudi Arabia.

\section{Financial Factor, Income Gap}

Among the many factors influencing specialty selection is anticipated future income. The income gap for Saudi physicians exists in a different form from that typically found in the United States and similar nations. The Saudi government pays the same base salary to all physicians; however, physicians in a specialty receive at least a $30 \%$ bonus to their base salary. ${ }^{1}$ Also, specialty physicians have more opportunity to increase their income by working part-time as a private provider, which is not a likely option for primary care physicians (PCP). The literature suggests that the perception that family physicians earn less income could at least diminish interest in that primary care specialty. ${ }^{2,3} \mathrm{~A}$ similar study demonstrated almost $40-60 \%$ of students planned to become specialist providers, seeking a path toward better income. ${ }^{4,5}$ There is both old and new evidence suggesting that half or more of medical students might choose primary care if income were improved for PCPs. 5,6

\section{Lifestyle}

Like income, the so-called lifestyle of a future medical career has become a determinant in students' specialty choice and may play a major role in the recent trend away from primary care. Definitions of lifestyle and the elements of its measurement varies among studies. Newton and colleagues ${ }^{7}$ defined a desirable career lifestyle as one that allows time off, opportunities to enjoy life outside of work, flexible work hours, time to pursue activities outside of work, and family time. Another report by Dezee and his colleagues ${ }^{8}$ states that lifestyle should include four themes: schedule control, financial aspects, off time, and work life. These criteria of lifestyle were found more influential than traditional motivators, such as incentives and training. ${ }^{9}$

Medical students are surrounded with negative impressions, from their training and the culture at large, regarding lifestyle in primary care. ${ }^{10,11}$ In addition, previous studies suggest that specialization is perceived to offer more control in the time spent by the doctor at work. ${ }^{12}$ Prestige is another factor of lifestyle which is used to differentiate between the medical specialties, affecting the choice of specialty. Unfortunately, primary health care is seen to lack prestige compared to other specialties. ${ }^{13,14}$

In this report, we present findings from a survey of 4th and 5th year medical students in Saudi Arabia regarding factors - specifically income and lifestyle factors - that may influence them in the specialty they anticipate selecting.

\section{Methods}

\section{Study Design and Participants}

Our investigation utilized a cross-sectional survey involving a self-administered questionnaire. This survey was conducted at the 10 medical schools in the Riyadh region of Saudi Arabia. The Riyadh region was chosen because it has several advantages that are not available in other locations within Saudi Arabia. First, it contains one third of all medical schools in Saudi Arabia. Second, it includes both public and private medical schools, and finally, the medical schools are within both urban and rural settings. The study population was comprised of all fourth- and fifth-year medical students at each medical school.

\section{Data Collection Protocol and Sample Size}

Data were collected through a paper, self-administered questionnaire. Data collection occurred six weeks after the beginning of 2019 the Fall semester, starting in October and lasted for four weeks. The questionnaire was pilot tested for understandability using a small subsample of those who shared the major characteristics of the target study population. 
All 1,600 fourth- and fifth-year medical students of both genders were eligible to participate in the survey. To ensure a higher response rate, the paper-andpencil questionnaire was group-administered to these students. We arranged in advance to have the students remain in their classroom past the end of class so that we could ask for study participation. Prior to the distribution of the questionnaire, informed consent was obtained from the potential participants about what participation in the study involved, so that they could make the decision about whether to engage in the research. The approval of the Institutional Review Boards (IRB) was obtained for the purpose of the study.

\section{Variables and Data Sources/Measurement}

The dependent variable for this study was choice of specialty: primary care or otherwise. Using previously established definitions per the Saudi Arabian Ministry of Health, we classified family medicine and preventive medicine as primary care specialties. ${ }^{15,16,17}$ Respondent were asked to indicate their first specialty choice in general. To better categorize levels of interest in the various specialties, students were also asked to rank three additional specialties in which they had the most interest and to identify three specialties that they were least interest in. Students then were asked directly about their desire to choose primary care as a career after they graduate.

We had two independent variables of interest: lifestyle and perceived income. The students were given a list of 26 specialties to rate according to a 3-point scale, with options of lifestyle friendly, lifestyle intermediate, and lifestyle unfriendly. Prior to rating the specialties, students were asked to rate the importance to their career choice of the following criteria: financial compensation, control of the work schedule, workload, enjoyment of the work environment, and enjoyment of this type of work. After that, we asked the students specifically about how they evaluate primary care careers in terms of these five criteria. Then, using a 3-level scale, students were asked to evaluate each medical specialty regarding lifestyle category.

The second independent variable was income disparity. Adapting Newton ${ }^{7}$ and his colleagues' survey question, a 4-point scale was used to rate the influence of each attribute on the students' selection of career specialties, with verbal anchors of "essential," "very important," "somewhat important," and "not important." Students were asked whether a primary care career provides an income that will allow them to live comfortably, provides an income sufficient to provide adequately for their family, and provides an adequate financial reward for the years of training required. Also, students were asked if the opportunity to work in the private sector is an incentive for excluding the primary care specialty in the career choice. Finally, several covariates were also collected including gender, age, marital status, the type of medical school, and geographical background.

\section{Analysis Methods}

Comparisons were made between the selection of students' two factors (lifestyle and income) to primary care with other specialties. For this report, the only dependent variable we utilized was choice of specialty: primary care. Based on previously established definitions, we classified family medicine and preventive medicine, as primary care careers. The variable was operationalized to reflect one of two possible mutually exclusive occurrences: (0) no primary care selected, meaning that family medicine, or preventive medicine were not indicated as the career choice; or (1) primary care selected, meaning that family medicine, or preventive medicine was indicated as the career choice.

Binary logistic regression was used to model the data, which was conducted in two ways. The first involved including all the variables in the model for each of the two factors: lifestyle and income. Second, we grouped the variables of each factor using the mean method, and then add them to the model. For the lifestyle factor, we summed the students' rating of each variable in the lifestyle part of the questionnaire, and then divided it by the number of variables, yielding an average score across the various dimensions of lifestyle with a lower score indicating a greater preference for primary care. A similar approach was taken for the income variable. We used this approach to be able to examine the overall importance of the set of dimensions defining each factor in selection of a career specialty. Statistical significance was assessed at the $p \leq 0.05$ level. We used the Hosmer-Lemeshow test for postestimation goodnessof-fit test. The result was insignificant with p-value of 0.963 , indicating that our model fit the data well. Also, Cronbach's alpha test was utilized to measure of internal consistency across the dimensions defining each factor, that is, how closely related a set of items are as a group. Scale reliability coefficient was 0.7285 , where $\mathrm{r}=0.7$ or greater considered as sufficiently reliable. All analyses were performed using STATA version 14.1 .

\section{Results}

\section{Response Rate and Characteristics by Specialty Choice}

The response rate was $64.0 \%$ with 1024 students who returned a questionnaire from the 1600 questionnaires distributed. Of those responding, 19 had missing data for either lifestyle or income questions and were thus excluded from the analysis. Hence, the final number of respondents included in the analysis was 1005 students. In our sample, there were 566 students in their fourth year and 439 in their fifth year from the 10 universities. Also, among the students, 359 were women ( $35.7 \%$ ) and 646 were male (64.3\%). Almost $97 \%$ of students were single. The sample included 118 ( $11.7 \%$ of whole) students from two rural universities, Shaqra University and Prince Sattam University. The proportion of students from private universities was $35.9 \%$ (361) belonging to four universities: Al-Faisal, Al-Farabi, Al-Maarefa and Dar Al Uloom.

Respondents were classified as to specialty choice: Primary Care versus non-Primary Care. As noted, primary care specialty was chosen when students ranked either family or preventive medicine among three of their specialty preferences. There were $284(28.26 \%)$ respondents who identified primary care specialties among their 3 preferences which differed across medical schools, ranging from $18.6 \%$ to $38 \%$ (see Table 1). At the rural medical schools, the percentage of those who favored primary care was $37.3 \%$ (44), while the percentage of those who preferred other specialties was $62.7 \%$ (74). At the private medical schools, $24.4 \%$ students (88) prefer to practice in primary care specialties. Notably, students who expressed increased desire to a choose primary care career had a relatively lower GPA compared to those who desired another specialty (Table 2).

Page 3/9 
TABLE 1 Demographic Characteristics and Specialties of Respondents

\begin{tabular}{|c|c|c|c|c|c|c|c|c|c|c|c|c|c|c|c|c|c|c|c|c|c|c|}
\hline \multicolumn{23}{|c|}{ Universities By (Year \& Specialty Choice) } \\
\hline \multirow{2}{*}{\multicolumn{2}{|c|}{$\begin{array}{l}\text { Year and } \\
\text { specialty }\end{array}$}} & \multicolumn{2}{|c|}{ DAU } & \multicolumn{2}{|l|}{ FU } & \multicolumn{2}{|c|}{ IMAMU } & \multicolumn{2}{|c|}{ KSAU-HS } & \multicolumn{2}{|l|}{ KUS } & \multicolumn{2}{|c|}{ PSAU[1] } & \multicolumn{2}{|c|}{$\mathrm{PNU}[2]$} & \multicolumn{2}{|c|}{ SU[3] } & \multicolumn{2}{|c|}{ UM } & \multicolumn{3}{|c|}{ Alfisal } \\
\hline & & $\mathrm{n}$ & $\%$ & $\mathrm{n}$ & $\%$ & $\mathrm{n}$ & $\%$ & $\mathrm{n}$ & $\%$ & $\mathrm{n}$ & $\%$ & $\mathrm{n}$ & $\%$ & $\mathrm{n}$ & $\%$ & $\mathrm{~N}$ & $\%$ & $\mathrm{n}$ & $\%$ & $\mathrm{n}$ & $\%$ & $\mathrm{~N}$ \\
\hline \multirow[t]{3}{*}{$\begin{array}{l}4^{\text {th }} \\
\text { Year }\end{array}$} & $\begin{array}{l}\text { Non } \\
\text { PCP }\end{array}$ & 18 & 78.3 & 29 & 85 & 64 & 69 & 70 & 75.3 & 102 & 80 & 24 & 68.6 & - & & 4 & 33 & 65 & 81 & 56 & 82 & 432 \\
\hline & PCP & 5 & 21.7 & 5 & 15 & 29 & 31 & 23 & 24.7 & 26 & 20 & 11 & 31.4 & - & & 8 & 67 & 15 & 19 & 12 & 18 & 134 \\
\hline & total & 23 & 288 & 34 & 100 & 93 & 100 & 93 & 100 & 128 & 100 & 35 & 100 & & & 12 & 100 & 80 & 100 & 68 & 100 & 566 \\
\hline \multirow[t]{3}{*}{$\begin{array}{l}5^{\text {th }} \\
\text { Year }\end{array}$} & $\begin{array}{l}\text { Non } \\
\text { PCP }\end{array}$ & 17 & 85 & 32 & 50 & 55 & 60 & 54 & 68.4 & 10 & 67 & 27 & 65.9 & 19 & 73 & 19 & 63 & 29 & 78 & 27 & 77 & 289 \\
\hline & PCP & 3 & 15 & 32 & 50 & 37 & 40 & 25 & 31.6 & 5 & 33 & 14 & 34.1 & 7 & 27 & 11 & 37 & 8 & 22 & 8 & 23 & 150 \\
\hline & total & 20 & 250 & 64 & 100 & 92 & 100 & 79 & 100 & 15 & 100 & 41 & 100 & 26 & 100 & 30 & 100 & 37 & 100 & 35 & 100 & 439 \\
\hline \multicolumn{2}{|c|}{$\begin{array}{l}\text { All PCP } \\
\text { Choice }\end{array}$} & 8 & 18.6 & 37 & 38 & 66 & 36 & 48 & 27.9 & 31 & 22 & 25 & 32.9 & 7 & 27 & 19 & 45 & 23 & 20 & 20 & 19 & 284 \\
\hline
\end{tabular}

TABLE 2 Specialty Preference and Students' Grade Point Average

\begin{tabular}{|c|c|c|c|c|c|c|}
\hline \multicolumn{2}{|c|}{ Year and specialty } & \multicolumn{4}{|l|}{ GPA } & \multirow[t]{2}{*}{ Total } \\
\hline & & $2-2.99$ & $3-3.74$ & $3.75-4.49$ & $4.5-5$ & \\
\hline \multirow[t]{2}{*}{$4^{\text {th }}$ year } & Non- PCP & 16 & 84 & 186 & 146 & \multirow[t]{4}{*}{1005} \\
\hline & PCP & 12 & 29 & 68 & 25 & \\
\hline \multirow[t]{2}{*}{$5^{\mathrm{TH}}$ year } & Non-PCP & 17 & 68 & 118 & 86 & \\
\hline & PCP & 9 & 44 & 69 & 28 & \\
\hline \multicolumn{2}{|c|}{$\%$ who prefer PCP } & 38.9 & 32.4 & 31.1 & 18.6 & 100 \\
\hline
\end{tabular}

\section{Influence of Lifestyle and Income on Career Preference.}

The result from the "all variables" model for the first independent variable shows, work /life balance and creativity and initiative environment were significantly associated with primary care selection $(p<0.05)$. The remaining lifestyle dimensions such as working for social change, high income potential and social recognition were not found to be important to choose of primary care $(p>0.05)$. For the grouping model, the responses showed us that a clear majority of students considered lifestyle characteristic to be a significant influence in their career decision $(P<0.05)$. The grand mean among students who responded to all eight characteristics was 3.11 (3.54 - 2.64) (see Figure 1). Also, we found that neither year of medical school nor the type of university type affected the student's overall rating.

In terms of ranking the friendliness of lifestyle associated with each specialty, the grand mean of the response in the sample was 1.768 , where the closer the rate to 1 , the more desirable of lifestyle spatiality, and the farther from 1, the less desirable. Of the twenty-eight specialties listed, students classified family medicine $($ mean $=1.5)$ beside dermatology $($ mean $=1.3)$ as lifestyle friendly specialties. In comparison, students classified surgery specialty as lifestyle unfriendly (mean = 2; see Figure 2).

For the income variable, the grand mean of all income variables was 3.1337, which may explain to us the significant relationship between students' specialty choices and income variables $(\mathrm{p}<0.005)$. Students rated "incentive" and "live comfortably" higher, [(3.340) and (3.330) respectively], and they rated "similar income to my peers in other specialties" as the lowest (2.820; see Figure 3).

\section{Discussion}

This study evaluated the influences of two factors: lifestyle and income on Saudi medical students' decisions to choose primary care as a career specialty. The study found that lifestyle factors were important considerations in the preference for a primary care career for both genders during their fourth or fifth years of medical school. The findings support our hypothesis that the perception of a worse lifestyle associated with primary care among medical students in Saudi Arabia negatively affects the choice of primary care as a career.

There were some differences among subgroups of students. First, fourth year students were more affected than their counterparts in the fifth year by lifestyle factors. Perhaps this is because students in fourth year are building their lifestyle perspective based on the influence of general attitudes rather than experience. Students in the fifth year begin their clerkships, and thus have increased exposure to the medical community such as physicians and residents and are closer to the actual lifestyle. This explanation is supported by social cognitive theory and previous published work. ${ }^{18,19}$ Second, men were significantly more affected by lifestyle consideration compared to women. This finding differs from previous studies. ${ }^{12}$ An explanation is that men in Saudi society face more responsibilities in terms of family obligations, unlike women, especially if we realize that the financial aspect is an essential part of the lifestyle. Third, 
the balance between work and personal life continues to get as much attention among students for both years and gender, which is confirmed through previous studies. ${ }^{20}$

The classification of specialties based on schedule control, financial aspects, off time, work life balance and prestige, which no other study of Saudi Arabian medical students has examined, gives some insights into specialty selectin by these students. Students viewed family medicine as lifestyle-friendly, similar to dermatology specialty and that is consistent among all respondents. This result is counter to earlier studies where the students ranked family medicine as lifestyle uncontrollable. ${ }^{12}$ In understanding this finding, we note that family physicians have fewer hours of work compared to other specialties in Saudi Arabia. Second, the government is the main employer that pays physicians though fixed salaries, unlike the situation in the United States where the payment depends on the number of visits.

Regarding the income factor, our respondents' views were largely consistent with previous studies. ${ }^{21,22}$ Students treated income as a critical element in their preference for primary care, especially among women students in their fourth year. One possible explanation of this finding is that students in private universities - where most female medical students attend - are not receiving a government scholarship unlike the fifth year or the rest of the students in public universities, where education is free. In our study, female students in private universities make up the majority of our sample of women (59.6\%). We initially hypothesize that the income disparity between primary care and other specialties negatively impacts the desire to choose primary care as a career among Saudi Arabia medical students. The logistic regression analysis confirmed that the ratio of students with a preference for primary care were 2.4 times more influenced by income factors compare to those with a preference for other specialties. These results are consistent with previous studies which find that income negatively affects career decisions, especially if the major is primary care. ${ }^{23}$

Our study has several potential limitations. First, the students are from only 10 of Saudi Arabia's medical schools. However, we tried to overcome this by ensuring the diversity in terms of the type of university: public and private, as well as location in the urban and rural areas. Furthermore, we took into consideration that our sample included the universities that admitted one gender only to ensure the representativeness of the universities that were in the study. Second, students' career preferences were assessed at a single point in time and may change by the time a final selection of specialty is made. Third, the students were asked to report their long-term specialty choice, rather than their actual entry into a preferred residency or fellowship. It is possible that a student stated plans to enter a career, such as a pediatrics subspecialty, and then could change his or her mind over the course of a pediatrics residency.

In summary, we found that medical students in Saudi Arabia preferred specialties other than primary care. Students who preferred the primary care specialty usually had a relatively lower GPA compared to those who preferred other specialties, and were more likely to be a students' in a rural-based medical school. Both lifestyle and income considerations affected the preference for primary care as a career choice.

\section{Declarations}

- Ethics approval and consent to participate

The research was reviewed and approved by research ethical committee at the Al-Imam Muhammad Ibn Saud University, Institutional Review Board (IRB Registration: HAPO-01-R-001). Also, we obtained the signature of participant on consent form and all methods in the study were carried out in accordance with relevant guidelines and regulations(a copy of the form attached).

- Consent for publication

Not applicable

- Availability of data and materials

Not applicable

- Competing interests

The authors declare that they have no competing interests

- Funding

Not applicable

- Authors' contributions

Ahmed Alhussain wrote the original manuscript, performed the analysis and interpret the results. Ronnie Horner reviewed and edited the manuscript. Abdullah Khoja, Janice Probst, and Robert Moran reviewed the manuscript.

- Acknowledgements

We would like to express our gratitude and sincere thanks to Ministry of Health in the Kingdom of Saudi Arabia and Al-Imam Muhammad Ibn Saud University for facilitating the mission to collect data.

- Authors' information 
${ }^{a}$ Health Services Policy and Management Department, University of South Carolina, Columbia, SC, USA; bepartment of Health Services Research and Adminsistration, College of Public Health, University of Nebraska Medical Center, Omaha, NE, USA; 'Public Health and Family Medicine Department, Al-Imam

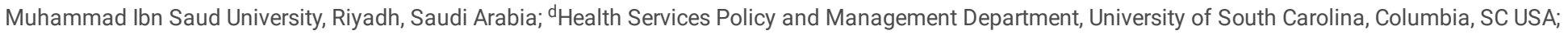
eEpidemiology and Biostatistics Department, University of South Carolina, Columbia, SC USA.

\section{References}

1. Ministry of Health. A guide of rights and financial benefits for Saudi health practitioners at the Ministry of Health. Riyadh. /Saudi Arabia: Ministry of Health; 2013.

2. Morra DJ, Regehr G, Ginsburg S. Medical students, money, and career selection: students' perception of financial factors and remuneration in family medicine. Fam Med. 2009;41(2):105-110.

3. Palmeri M, Pipas C, Wadsworth E, Zubkoff M. Economic impact of a primary care career: a harsh reality for medical students and the nation. Acad Med. 2010;85(11):1692-1697. doi:10.1097/ACM.0b013e3181f5b754

4. Bale AG, Coutinho K, Swan KG, Heinrich GF. Increasing educational indebtedness influences medical students to pursue specialization: a military recruitment potential?. Mil Med. 2013;178(2):202-206. doi:10.7205/milmed-d-12-00244

5. DeZee KJ, Maurer D, Colt R, et al. Effect of financial remuneration on specialty choice of fourth-year U.S. medical students. Acad Med. 2011;86(2):187193. doi:10.1097/ACM.0b013e3182045ec9

6. Rosenthal MP, Diamond JJ, Rabinowitz HK, et al. Influence of income, hours worked, and loan repayment on medical students' decision to pursue a primary care career. JAMA. 1994;271(12):914-917.

7. Newton DA, Grayson MS, Thompson LF. The variable influence of lifestyle and income on medical students' career specialty choices: data from two U.S. medical schools, 1998-2004. Acad Med. 2005;80(9):809-814. doi:10.1097/00001888-200509000-00005

8. Dezee KJ, Corriere MD, Chronister SM, et al. What does a good lifestyle mean to you? Perspectives of 4th-year U.S. medical students with military service obligations in 2009. Teach Learn Med. 2012;24(4):292-297. doi:10.1080/10401334.2012.715264

9. Dorsey ER, Jarjoura D, Rutecki GW. Influence of controllable lifestyle on recent trends in specialty choice by US medical students [published correction appears in JAMA. 2003 Nov 26;290(20):2666]. JAMA. 2003;290(9):1173-1178. doi:10.1001/jama.290.9.1173

10. Phillips J, Weismantel D, Gold K, Schwenk T. How do medical students view the work life of primary care and specialty physicians?. Fam Med. 2012;44(1):7-13

11. Barber S, Brettell R, Perera-Salazar R, Greenhalgh T, Harrington R. UK medical students' attitudes towards their future careers and general practice: a crosssectional survey and qualitative analysis of an Oxford cohort. BMC Med Educ. 2018;18(1):160. Published 2018 Jul 4. doi:10.1186/s12909-018-1197-z

12. Dorsey ER, Jarjoura D, Rutecki GW. The influence of controllable lifestyle and sex on the specialty choices of graduating U.S. medical students, 19962003. Acad Med. 2005;80(9):791-796. doi:10.1097/00001888-200509000-00002

13. Villanueva T. Family Medicine, the specialty of the future: the Portuguese situation within the European context. Int Arch Med. 2009;2(1):36. Published 2009 Nov 11. doi:10.1186/1755-7682-2-36

14. Kiolbassa K, Miksch A, Hermann K, et al. Becoming a general practitioner-which factors have most impact on career choice of medical students?. BMC Fam Pract. 2011;12:25. Published 2011 May 9. doi:10.1186/1471-2296-12-25

15. Shi L, Starfield B, Kennedy B, Kawachi I. Income inequality, primary care, and health indicators. J Fam Pract. 1999;48(4):275-284.

16. Shi L, Macinko J, Starfield B, Politzer R, Xu J. Primary care, race, and mortality in US states. Soc Sci Med. 2005;61(1):65-75. doi:10.1016/j.socscimed.2004.11.056

17. Starfield B. Primary Care in the United States. International Journal of Health Services. 1986;16(2):179-198. doi:10.2190/0DJ6-7LP0-9EWW-66FB

18. Clinite KL, DeZee KJ, Durning SJ, et al. Lifestyle factors and primary care specialty selection: comparing 2012-2013 graduating and matriculating medical students' thoughts on specialty lifestyle. Acad Med. 2014;89(11):1483-1489. doi:10.1097/ACM.0000000000000487

19. Bandura A. Social foundations of thought and action. Englewood Cliffs, NJ./USA: Prentice Hall; 1986.

20. Gander P, Briar C, Garden A, Purnell H, Woodward A. A gender-based analysis of work patterns, fatigue, and work/life balance among physicians in postgraduate training. Acad Med. 2010;85(9):1526-1536. doi:10.1097/ACM.0b013e3181eabd06

21. Jolly P. Medical school tuition and young physicians' indebtedness. Health Aff (Millwood). 2005;24(2):527-535. doi:10.1377/hlthaff.24.2.527

22. Campos-Outcalt D. Debt and specialty preference. Fam Med. 2011;43(3):205-206.

23. Thornton J, Esposto F. How important are economic factors in choice of medical specialty?. Health Econ. 2003;12(1):67-73. doi:10.1002/hec.682

\section{Figures}




\section{Lifestyle: How important are the following considerations?}

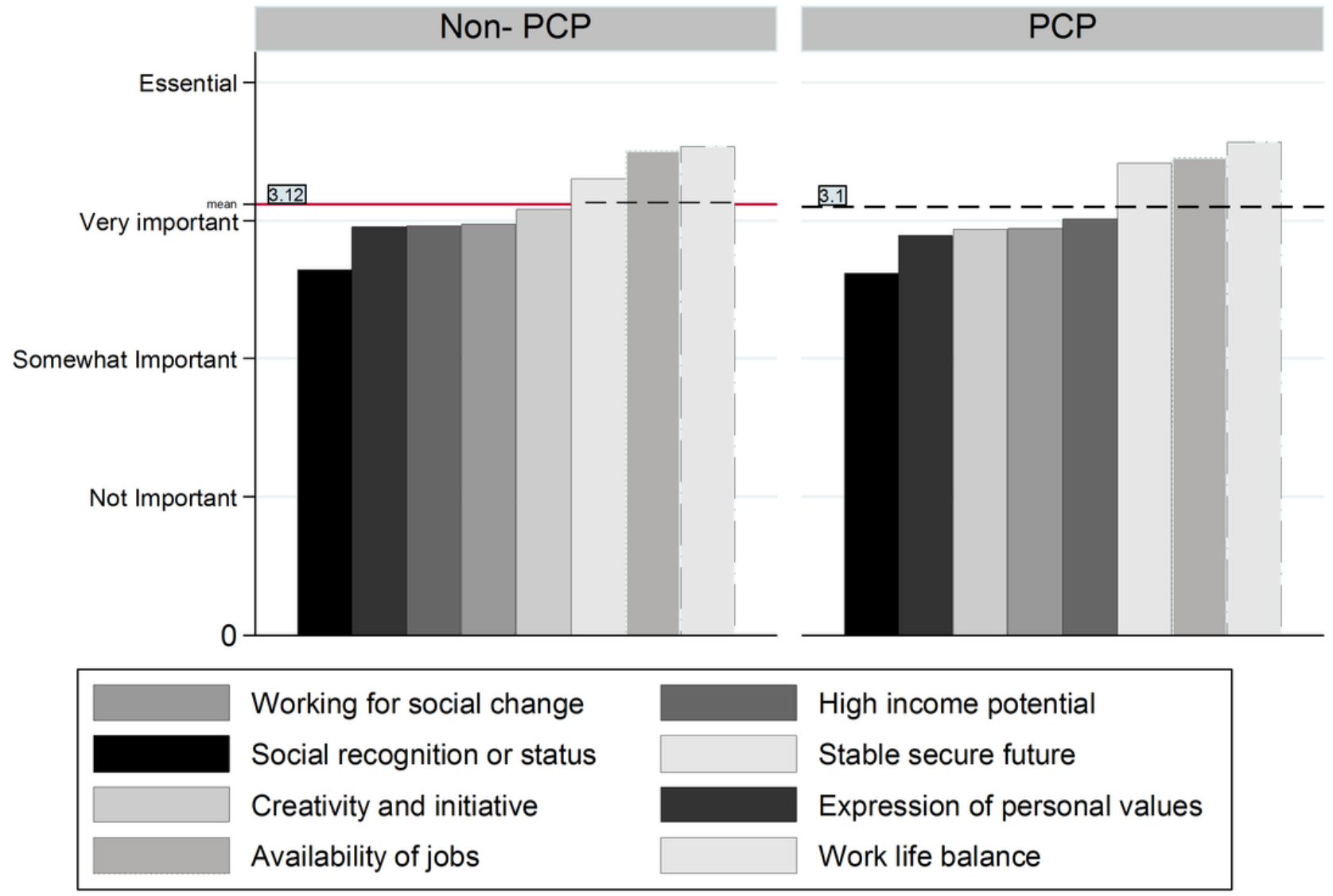

Figure 1

Lifestyle Variables that Influence Career Choices. 


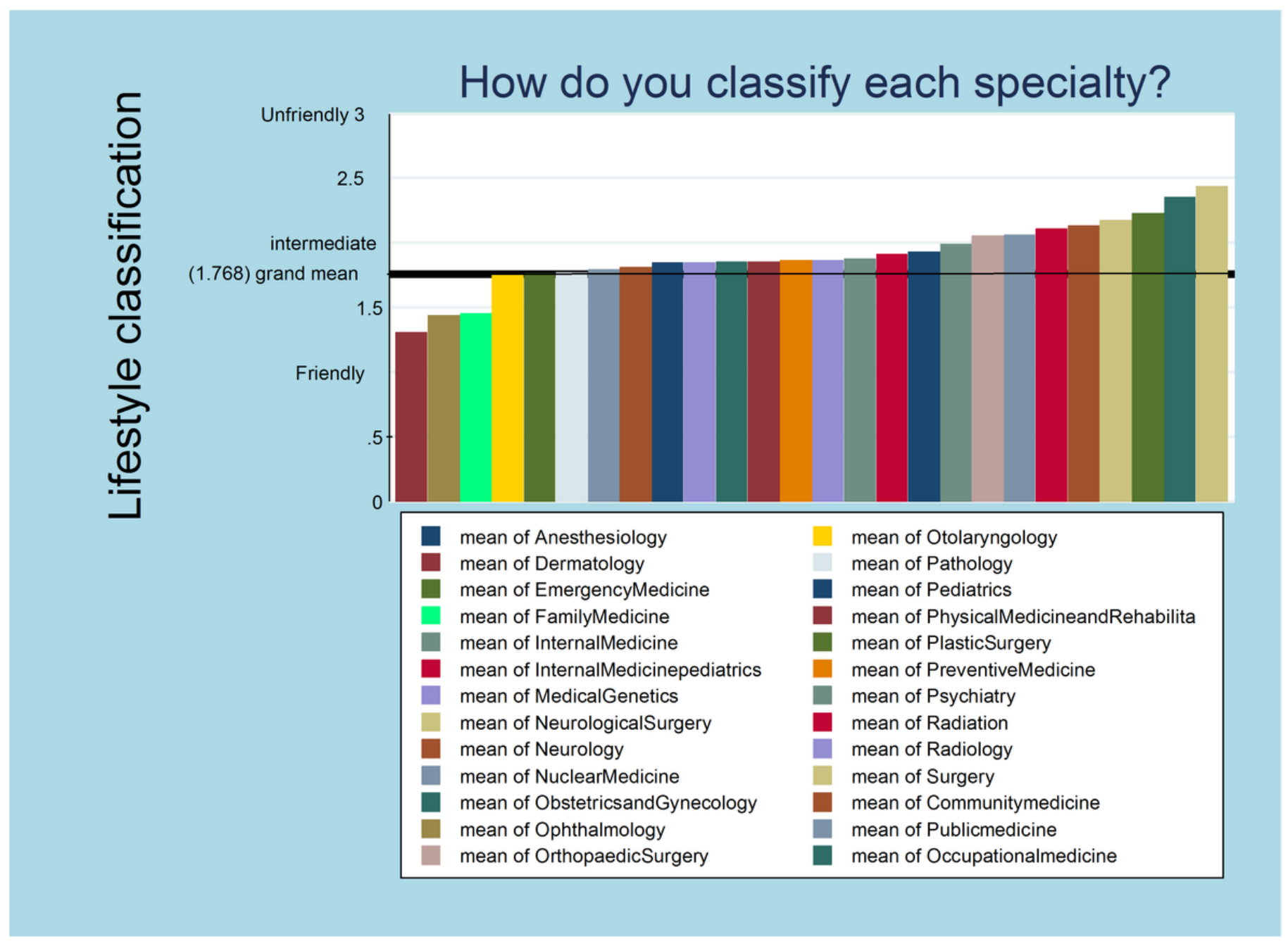

\section{Figure 2}

Specialty classifications based on Lifestyle categories (schedule control, financial aspects, off time, and work life, prestige). 
Income : How influential were the following in helping you choose your specialty?

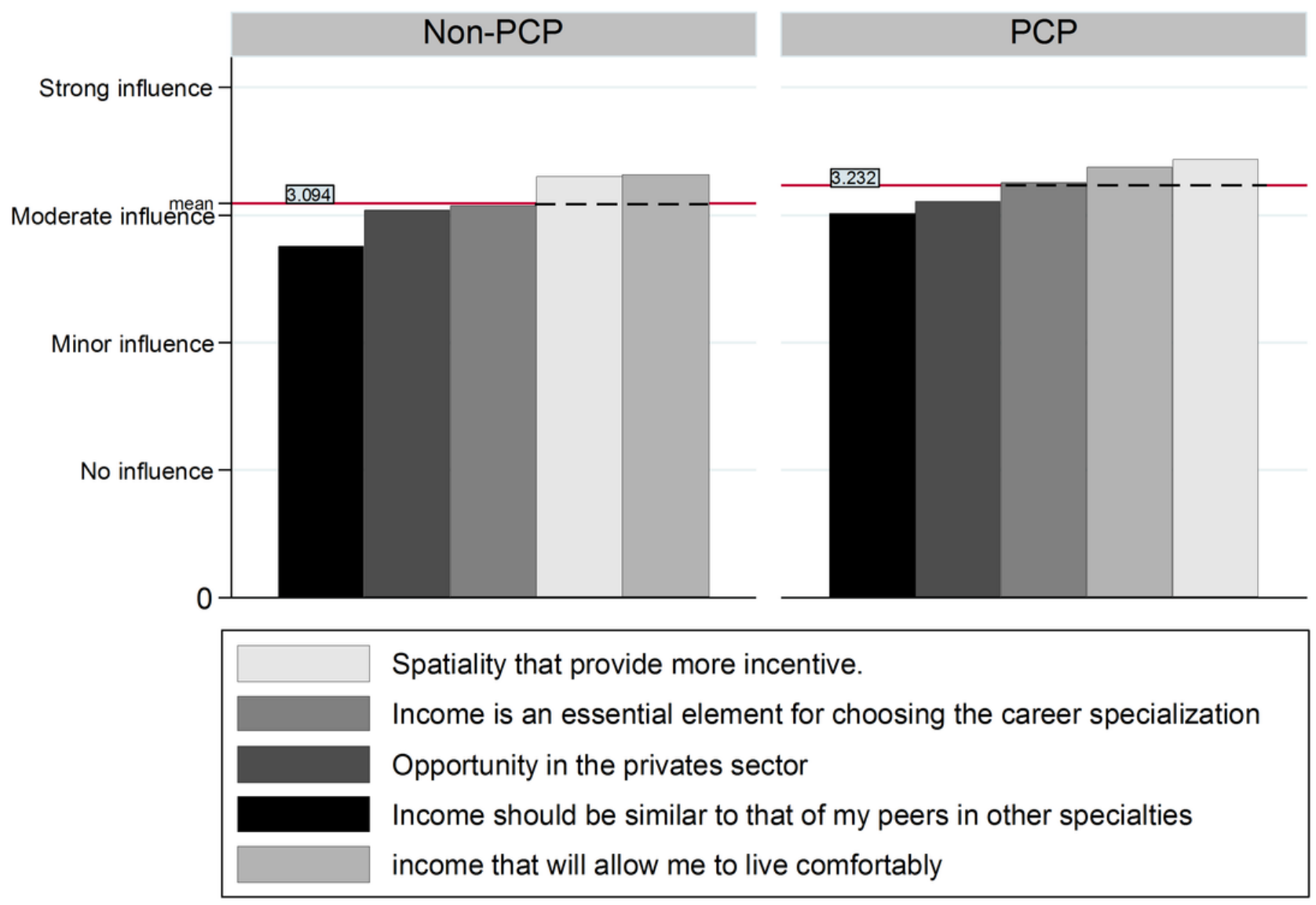

Figure 3

Specialty Preferences with Income Variables. 